\title{
Short communication: Detection of human Torque teno virus in the milk of water buffaloes (Bubalus bubalis)
}

\author{
S. Roperto, ${ }^{* 1}$ O. Paciello, ${ }^{*}$ F. Paolini,† U. Pagnini, ${ }^{*}$ E. Palma,ł R. Di Palo,§ V. Russo, ${ }^{*}$ F. Roperto, ${ }^{*}$ \\ and A. Venuti† \\ *Department of Pathology and Animal Health, Faculty of Veterinary Medicine, Naples University Federico II, Naples, Italy \\ †Laboratory of Virology, Regina Elena Cancer Institute, Rome, Italy \\ łDipartimento di Scienze Farmacobiologiche, Facoltà di Farmacia, Università di Catanzaro Magna Græcia, 88100 Catanzaro, Italy \\ §Dipartimento di Science Zootecniche ed Ispezione degli Alimenti, Facoltà di Medicina Veterinaria, Università di Napoli 'Federico II', Napoli, Italy
}

\section{ABSTRACT}

Forty-four raw milk and 15 serum samples from 44 healthy water buffaloes reared in Caserta, southern Italy, the most important region in Europe for buffalo breeding, were examined to evaluate the presence of Torque teno viruses (TTV) using molecular tools. Furthermore, 8 pooled pasteurized milk samples (from dairy factories having excellent sanitary conditions) and 6 Mozzarella cheese samples were also tested. Four of the cheese samples were commercial Mozzarella cheese; the remaining 2 were prepared with TTV-containing milk. Human TTV were detected and confirmed by sequencing in 7 samples of milk (approximately 16\%). No TTV were found in serum, pooled pasteurized milk, or Mozzarella cheese samples. The samples of Mozzarella cheese prepared with TTV-containing milk did not show any presence of TTV, which provides evidence that standard methodological procedures to prepare Mozzarella cheese seem to affect viral structure, making this food fit for human consumption. The 7 TTV species from water buffaloes were identified as genotypes corresponding to the tth31 (3 cases), sle 1981, sle 2031, and NLC030 (2 cases each) human isolates. Although cross-species infection may occur, detection of TTV DNA in milk but not in serum led us to believe that its presence could be due to human contamination rather than a true infection. Finally, the mode of transmission of TTV has not been determined. Contaminated of the food chain with TTV may be a potential risk for human health, representing one of the multiple routes of infection.

Key words: water buffalo, Torque teno virus, milk, Mozzarella cheese

Torque teno virus (TTV) is a novel DNA virus found in 1997 in Japan from a patient with posttransfusion

Received March 31, 2009.

Accepted August 6, 2009.

${ }^{1}$ Corresponding author: sante.roperto@unina.it hepatitis of unknown etiology (Nishizawa et al., 1997). It was recently named Torque teno virus after the Latin for "thin necklace" (Hino and Miyata, 2007). At least 39 genotypes of Torque teno viruses have been identified and phylogenetic analysis revealed 5 major groups (groups 1 to 5; Okamoto, 2009a). They are classified into the genus Anellovirus, reflecting the organizational circular arrangement of the TTV genome (Biagini, 2009).

Torque teno viruses are spread globally and appear to frequently infect both rural and urban human populations (Biagini, 2004). Infections of TTV are not restricted to human hosts: TTV infection has been reported in nonhuman primates (Abe et al., 2000). Furthermore, TTV DNA has been detected in serum and feces samples of farm animals such as pigs, cows, chickens, and sheep (Leary et al., 1999; Brassard et al., 2008). Genomic characterization has been performed on species-specific TTV that infect domestic animals including pigs, cats, and dogs (Okamoto et al., 2000).

Recently, TTV infection has been detected in camels (Al-Moslih et al., 2007). The aim of the present paper was to report the incidence of human TTV genotypes detected in the milk of water buffaloes and emphasize the potential role of the food chain in human TTV infection.

Forty-four raw milk and 15 serum samples were collected from 44 healthy water buffaloes chosen at random from 3 buffalo breeding operations in the area of Caserta, southern Italy, which is the most important region in Europe for buffalo breeding. All 3 buffalo breeding operations were characterized by excellent sanitary conditions. Furthermore, 8 pooled pasteurized milk samples were obtained from 4 dairy factories known to collect large quantities of commercial buffalo milk and to have very good sanitary requirements. Milk was pasteurized by the continuous HTST method $\left(72.5^{\circ} \mathrm{C}\right.$ for $\left.20 \mathrm{~s}\right)$.

Six Mozzarella cheese samples were also tested; 4 were from quantities on sale in a commercial market, and 2 were experimentally prepared with TTV-contain- 
ing milk obtained from a buffalo breeder in the area of Caserta, Italy. Commercial Mozzarella cheese was prepared using traditional whey starter according to the procedures provided by the European Regulation $1107 / 96$ for the European products having a protected denomination of origin. Briefly, milk was curdled by rennet addition in approximately $30 \mathrm{~min}$. After milling the curd and partially separating the whey, curd ripening was conducted by submerging it under whey for 3 to $4 \mathrm{~h}$ to reach a $\mathrm{pH}$ value of approximately 4.8 . At this time, the curd was cut into small pieces (about 1 linear $\mathrm{cm}$ ) and stretching was begun by addition of boiling water $\left(98^{\circ} \mathrm{C}\right)$ in a curd/water ratio of $1: 2(\mathrm{wt} /$ wt) at temperature of 60 to $65^{\circ} \mathrm{C}$ under acid conditions ( $\mathrm{pH} 4.8$ ).

Contaminated milk used to prepare Mozzarella cheese was pasteurized by the batch method in a pilot plant in that was in a controlled area and was limited to authorized personnel. Because of the small quantities of contaminated milk, a jacketed vat surrounded by circulating steam was used to heat milk to $65^{\circ} \mathrm{C}$ for a holding period of 30 min followed by rapid cooling to approximately $36^{\circ} \mathrm{C}$ under continuous agitation. Phosphatase-negative milk was subsequently curdled to obtain cheese with the same commercial procedures as the industrial procedures.

One hundred-microliter aliquots of milk and serum samples were used for DNA extraction by using the QIAamp Mini kit (Qiagen, Milan, Italy) following the manufacturer's instructions. Mozzarella cheese was processed by the Nucleospin food kit (Macherei-Nagel, Bethlehem, PA) to extract genomic DNA according to the manufacturer's instruction.

All specimens were tested for the presence of TTV DNA by PCR. Five-microliter aliquots of DNA were amplified using 2 sets of nested primers derived from the conserved $5^{\prime}$ untranslated region of the TTV genome; the nested primers used were NG054/147 for the outer reaction and NG133/132 for the inner reaction (Okamoto et al., 1999). Both outer and inner PCR amplifications were undertaken in $50-\mu \mathrm{L}$ reaction mixtures containing $50 \mu M$ of each primer, $2 \mathrm{mM} \mathrm{MgCl} 2,2.5$ $\mathrm{m} M$ of each dNTP, and 1 unit of thermostable Platinum Taq (Invitrogen, Milan, Italy) with the following cycles: initial $2.5 \mathrm{~min}$ denaturation at $95^{\circ} \mathrm{C}$, followed by 35 cycles of $50^{\circ} \mathrm{C}\left(55^{\circ} \mathrm{C}\right.$ for inner primers) for $30 \mathrm{~s}$, $72^{\circ} \mathrm{C}$ for $1 \mathrm{~min}, 95^{\circ} \mathrm{C}$ for $30 \mathrm{~s}$, and final elongation at $72^{\circ} \mathrm{C}$ for $10 \mathrm{~min}$. Three microliters of the outer PCR was used for the inner PCR. To increase the sensitivity of the screening, samples were analyzed under the same PCR conditions but using the primer set B as reported by Leary et al. (1999). Positive and negative controls (TTV-positive DNA from human sera and no DNA, respectively) were included in each amplification.
Table 1. Detection rates of Torque teno virus (TTV) in milk and sera from water buffaloes in southern Italy

\begin{tabular}{lccc} 
& & \multicolumn{2}{c}{ Positive for TTV } \\
\cline { 3 - 4 } Sample & $\begin{array}{c}\text { Samples } \\
\text { tested, } \mathrm{n}\end{array}$ & $\mathrm{n}$ & $\%$ \\
\hline Milk & 44 & 7 & 15.90 \\
Serum & & 15 & 0 \\
Pooled milk & 8 & 0 & 0 \\
Mozzarella cheese & 6 & 0 & 0 \\
\hline
\end{tabular}

Amplified products were submitted to $2.5 \%$ agarose gel electrophoresis under constant voltage $(90 \mathrm{~V})$ for approximately $40 \mathrm{~min}$. The resolved bands were visualized under UV light.

Viral typing was achieved by direct sequencing of PCR amplification. Briefly, amplicons were purified by affinity chromatography with the PCR purification kit (Qiagen) and subjected to automated sequencing (Biogen GeneLab, Rome, Italy). The obtained sequences were aligned to prototype viral sequences with the BLAST (Basic Local Alignment Search Tool) program (http://www.ncbi.nlm.nih.gov/BLAST).

Torque teno viruses were detected in 7 out of 44 milk samples (about 16\%) as shown in Table 1. Molecular investigations failed to detect TTV in serum samples, pooled pasteurized milk samples, or Mozzarella cheese samples. The presence of a 132-bp amplified product by agarose gel was indicative of a positive result that was further confirmed by sequencing. A representative example of this analysis is showed in Figure 1.

The same samples were analyzed with a different set of primers amplifying a different TTV region; this analysis did not reveal additional positive samples and confirmed the previous results (data not shown). Table 2 shows the distribution of TTV DNA genotypes. Sequences were aligned and compared with the sequences in the database. The sequences showed high homology $(>95 \%)$ with the following human isolates: th31 (3 cases), sle 1981, sle 2031, and NLC030 (2 cases each). Therefore, all the detected TTV were homologous to human isolates.

Conflicting opinions exist on the potential of TTV to cause disease, including cancer, because of their wide presence globally in human populations; however, TTV infection has been associated with liver (Comar et al., 2006) and respiratory diseases (Bando et al., 2008) as well as hematological disorders (Figueiredo et al., 2007). Torque teno viruses appear to be involved in idiopathic inflammatory myopathies (Gergely et al., 2005 ) and in some skin disorders such as bullous pemphigoid (Blazsek et al., 2008). It has been speculated that TTV may be involved in indirect carcinogenesis mostly via a dysfunction of the immune system (zur 


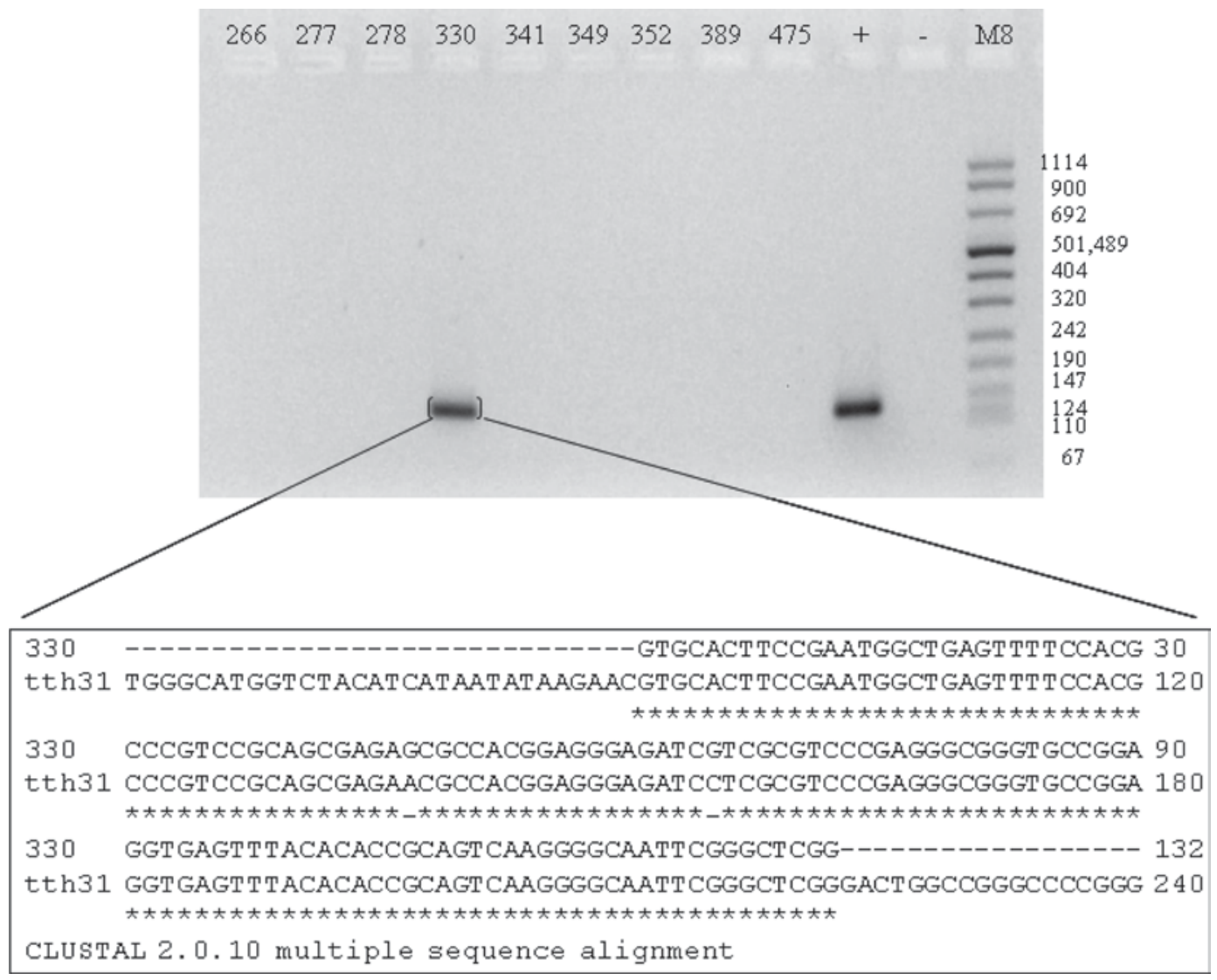

Figure 1. Agarose gel electrophoresis of the amplified products: DNA extracted from raw milk samples was subjected to nested PCR with NG primers. The length of the Torque teno virus (TTV) amplification product was $132 \mathrm{bp}$. Numbers over lanes correspond to different samples; $+=$ DNA from TTV-positive human serum; - = no DNA; M8 = molecular mass marker type VIII (Roche Applied Science, Monza, Italy), sizes (bp) shown on the right. The result of the direct sequencing of the amplified product is shown in the bottom panel with the alignment to the sequence of the tth31 isolate (emb AJ620225.1; http://www.ncbi.nlm.nih.gov/sites/entrez?db=nuccore) by the EBI ClustalW2 software (http:// www.ebi.ac.uk/Tools/clustalw2/index.html).

Hausen and de Villiers, 2009). It has been suggested that TTV are co-infecting viruses, thus, promoting and enhancing the pathological effects of other infectious agents. High co-prevalence of TTV and human herpes virus 8 has been reported in patients suffering from Kaposi's sarcoma (Girard et al., 2007); co-infection of TTV and human papillomavirus has been documented in patients with laryngeal carcinoma (Szládek et al., 2005). High titers of TTV DNA have been found in patients infected with human immunodeficiency virus (Thom and Petrik, 2007). Furthermore, the identification of a high level of TTV in colorectal cancer tissues may indicate an increased risk for such cancers (de Villiers et al., 2007).

Many aspects of TTV infection, including the precise host range and cross-species, remain to be elucidated (Okamoto, 2009b). However, a high incidence of human TTV genotypes 11 and 16 has been detected in the serum $(38.2 \%)$ and milk $(37.5 \%)$ of camels, which sug- gests that cross-species infection may occur (Al-Moslih et al., 2007).

We found a high incidence (approximately 16\%) of human TTV genotypes in the milk of water buffaloes, the serum of which was negative; furthermore, Mozzarella cheese produced with TTV-containing milk was also negative for TTV. The use of only one set of

Table 2. Torque teno virus (TTV) genotype distribution in raw milk of water buffaloes

\begin{tabular}{lll}
\hline Sample & TTV isolate detected & Database accession no. \\
\hline 276 & tth31 & emb AJ620225.1 \\
330 & tth31 & emb AJ620225.1 \\
550 & tth31 & emb AJ620225.1 \\
602 & sle2031 & emb AM711979.1 \\
723 & NLC030 & dbj AB038631.1 \\
897 & sle1981 & emb AM712048.1 \\
952 & NLC030 & dbj AB038631.1 \\
\hline${ }^{1}$ Database & URL: http://www.ncbi.nlm.nih.gov/sites/entrez?db \\
$=$ nuccore & &
\end{tabular}


primers may cause underestimation of positive samples; therefore, all specimens were analyzed with a second set of primers that has previously been shown to amplify a larger number of TTV (Leary et al., 1999). The additional set of primers did not reveal any additional positive samples and confirmed the presence of the same human isolates.

Therefore, we believe that TTV presence in the milk of the examined buffaloes is due to human contamination rather than a true mammary infection; furthermore, routine methodological procedures for preparing Mozzarella cheese seem to affect viral structure, making the food fit for human consumption. High temperature combined with other parameters such as the acidity conditions of curdled milk may be effective at inactivating the virus or decreasing the viral titer. A recent paper about the resistance of porcine circovirus 2 (PCV2) and chicken anemia virus (CAV), 2 well-known TTV-related viruses, showed that pasteurization above $70^{\circ} \mathrm{C}$ is effective at eliminating PCV2 and CAV infectivity (Welch et al., 2006). Our results appear to conflict with the findings reported in camel milk (Al-Moslih et al., 2007). In that study, the authors stated that pasteurization of camel milk did not affect TTV, but the authors did not report any pasteurization method, particularly the temperature and holding time. Further specific investigations are needed. In particular, quantitative real-time PCR investigations could be very useful to determine the difference, if any, in the starting quantity of viral DNA in milk from infected animals (the Al-Moslish et al., 2007 study) and in contaminated milk (our study).

Although horizontal routes, particularly droplet infection, appear to be involved in transmission of Anelloviruses (Okamoto, 2009a), we believe that it is important to clarify the significance of the presence of TTV as a food risk factor. In this context, it has been suggested that the effect of TTV presence in livestock population for the agricultural food chain should be further investigated (Brassard et al., 2008).

Our study shows that TTV-contaminated milk of farm animals can be an important route resulting in human exposure to such agents. Raw milk represents a potential mode of viral transmission and may contribute to the spread of viruses in human populations. Our observations raise questions about the presence of TTV in the food chain as an important risk factor of disease and whether viral investigations must be carried out to ensure the safety of animal food for human consumption.

\section{ACKNOWLEDGMENTS}

This work was partially supported by grants of Ministero della Salute, Ministero Italiano dell'Università e
Ricerca Scientifica; Ministero Italiano delle Politiche Agricole, Alimentari e Forestali; legge Regionale n. 5; Assessorato alla Sanità of the Regione Basilicata and Campania; Dipartimento Agricoltura, Foreste, Forestazione Caccia e Pesca of Regione Calabria, Arpacal- Centro di Eccellenza in Tossicologia Alimentare, Regione Calabria. We thank E. Massari and G. Toma from the Azienda Unità Sanitaria Locale PZ/2; G. Salvatore, responsible for Veterinary Office and Hygiene Food of Regione Basilicata; G. Di Domenico and G. Marino from the Azienda Sanitaria Locale SA/3; and F. Logozzo from Regione Calabria for their collaboration.

\section{REFERENCES}

Abe, K., T. Inami, K. Ishikawa, S. Nakamura, and S. Goto. 2000. TT virus infection in nonhuman primates and characterization of the viral genome: identification of simian TT virus isolates. J. Virol. 74:1549-1553.

Al-Moslih, M. I., H. Perkins, and Y.-W. Hu. 2007. Genetic relationship of Torque Teno virus (TTV) between humans and camels in United Arab Emirates (UAE). J. Med. Virol. 79:188-191.

Bando, M., M. Takahashi, S. Ohno, T. Hosono, M. Hironaka, H. Okamoto, and Y. Sugiyama. 2008. Torque teno virus DNA titre elevated in idiopathic pulmonary fibrosis with primary lung cancer. Respirology 13:263-269.

Biagini, P. 2004. Human circoviruses. Vet. Microbiol. 98:95-101.

Biagini, P. 2009. Classification of TTV and related viruses (Anelloviruses). Curr. Top. Microbiol. Immunol. 341:21-33.

Blazsek, A., P. Sillo, N. Ishii, P. Gergely, G. Poor, K. Preisz, T. Hashimoto, M. Medvecz, and S. Kárpáti. 2008. Searching for foreign antigens as possible triggering factors of autoimmunity: Torque Teno virus DNA prevalence is elevated in sera of patients with bullous pemphigoid. Exp. Dermatol. 17:446-454.

Brassard, J., M.-J. Gagné, L. Lamoureux, G. D. Inglis, D. Leblanc, and A. Houde. 2008. Molecular detection of bovine and porcine Torque teno virus in plasma and feces. Vet. Microbiol. 126:271-276.

Comar, M., G. Dal Molin, P. D'Agaro, S. L. Crocè, C. Tiribelli, and C. Campello. 2006. HBV, HCV, and TTV detection by in situ polymerase chain reaction could reveal occult infection in hepatocellular carcinoma. J. Clin. Pathol. 59:526-529.

de Villiers, E. M., M. Bulajic, C. Nitsch, D. Kecmanovic, M. Pavlov, A. Kopp-Schneider, and M. Löhr. 2007. TTV infection in colorectal cancer tissues and normal mucosa. Int. J. Cancer 121:2109 2112.

Figueiredo, C. P., H. C. Franz-Vasconcelos, G. Giunta, T. L. Mazzuco, T. Caon, A. L. Fernandes, C. M. Simões, V. L. Antunes, C. Niel, and C. R. Barardi. 2007. Detection of Torque teno virus in EpsteinBarr positive and negative lymph nodes of patients with Hodgkin lymphoma. Leuk. Lymphoma 48:731-735.

Gergely, P., A. Blazsek, P. K. Danko, A. Ponyi, and G. Poor. 2005. Detection of TT virus in patients with idiopathic inflammatory myopathies. Ann. N. Y. Acad. Sci. 1050:304-313.

Girard, C. L., L. Ottomani, J. Ducos, O. Dereure, M. J. Carles, and B. Guillot. 2007. High prevalence of Torque teno (TT) virus in classical Kaposi's sarcoma. Acta Derm. Venereol. 87:14-17.

Hino, S., and H. Miyata. 2007. Torque teno virus (TTV): Current status. Rev. Med. Virol. 17:45-57.

Leary, T. P., J. C. Erker, M. L. Chalmers, S. M. Desai, and I. K. Mushahwar. 1999. Improved detection systems for TT virus reveal high prevalence in humans, non-human primates and farm animals. J. Gen. Virol. 80:2115-2120.

Nishizawa, T., H. Okamoto, K. Konishi, H. Yoshizawa, Y. Miyakawa, and M. A. Mayuni. 1997. A novel DNA virus (TTV) associated with elevated transaminase levels in post-transfusion hepatitis of unknown etiology. Biochem. Biophys. Res. Commun. 241:92-97. 
Okamoto, H. 2009a. History of discoveries and pathogenicity of TT viruses. Curr. Top. Microbiol. Immunol. 341:1-20.

Okamoto, H. 2009b. TT viruses in animals. Curr. Top. Microbiol. Immunol. 341:35-52.

Okamoto, H., T. Nishizawa, M. Ukita, M. Takahashi, M. Fukuda, H. Iizuka, Y. Miyakawa, and M. Mayumi. 1999. The entire nucleotide sequence of a TT virus isolate from the United States (TUSOD): Comparison with reported isolates and phylogenetic analysis. Virology 259:437-448.

Okamoto, H., M. Takahashi, T. Nishizawa, A. Tawara, K. Fukai, U. Muramatsu, Y. Naito, and A. Yoskikawa. 2000. Genomic characterization of TT viruses (TTVs) in pigs, cats and dogs and their relatedness with species-specific TTVs in primates and tupaias. J. Gen. Virol. 83:1291-1297.
Szládek, G., A. Juhász, G. Kardos, K. Szöke, T. Major, I. Sziklai, I. Tar, I. Márton, L. Gergely, and K. Szarka. 2005. High coprevalence of genogroup $1 \mathrm{TT}$ virus and human papillomavirus is associated with poor clinical outcome of laryngeal carcinoma. J. Clin. Pathol. 58:402-405.

Thom, K., and J. Petrik. 2007. Progression towards AIDS leads to increased torque teno virus and torque teno minivirus titers in tissues of HIV infected individuals. J. Med. Virol. 79:1-7.

Welch, J., C. Bienek, E. Gomperts, and P. Simmonds. 2006. Resistance of porcine circovirus and chicken anemia virus to virus inactivation procedures used for blood products. Transfusion 46:1951-1958.

zur Hausen, H., and E.-M. de Villiers. 2009. TT viruses: Oncogenic or tumor-suppressive properties? Curr. Top. Microbiol. Immunol. 331:109-116. 